\title{
Build-up and Performance test of a Novel Solar Thermal Roof for heat pump operation
}

\author{
Mahmut Sami Buker ${ }^{1 *}$, Saffa B. Riffat ${ }^{1}$
}

${ }^{1}$ Institute of Sustainable Energy Technology, University of Nottingham, Nottingham, NG7 2RD, UK

\section{*laxmsb@nottingham.ac.uk}

\begin{abstract}
The worldwide increase in energy demand and fossil fuel prices have loaded ever-increasing pressure on identifying and implementing new means to utilize clean and efficient energy resources. Due to the environmental benefits, technical and economic possibilities of Solar-Assisted Heat Pump Systems (SAHPS), there has been a growing interest for such hybrid systems that display a variety of system designs in various climates. A Novel Solar Thermal Roof collector was developed by primarily exploiting components and techniques that are widely available on the market and coupled with a commercial heat pump unit. In this study, this particular SAHPS was experimentally tested and system performance was investigated yet, the analysis based on indoor and outdoor testing predominantly focuses on the solar thermal roof collector. A detailed thermal model was developed to describe the system's operation. Then a computer model was set-up by using Engineering Equation Solver (EES) to carry out the numerical computations of the governing equations. Analysis show that the difference in water temperature could reach up to $18^{\circ} \mathrm{C}$ and thermal efficiency of the roof system would achieve up to $26 \%$. Data processing of the series covering the test period represents that Coefficient Performance of the heat pump $\left(C O P P_{H P}\right)$ and overall system (COPSYS) averages were attained as $C O P_{H P}=3.01$ and $C O P_{S Y S}=2.29$, respectively.
\end{abstract}

Keywords: Solar Thermal Roof Collector, Polyethylene heat exchanger, Heat Pump, Numerical model, Energy Analysis, Uncertainty Analysis

\section{Introduction}

Excessive increase in energy demand, escalating fossil fuel prices, global warming and climate changes have brought a new dimension to seek for sustainable energy resources with a minimum impact on the environment. Solar energy, as a clean, sustainable, and environment friendly energy source, can play an important role for the proper use of energy resources [1]. Significant utilization of solar energy takes place especially in regions where relatively lower temperature (less than $100{ }^{\circ} \mathrm{C}$ ) is obtained [2].

Solar collectors for domestic hot water production and space heating have been extensively used, especially where the solar radiation is abundant. However, conventional solar thermal collectors have some practical drawbacks, which include susceptibility to damage during transportation which could lead to large financial 
losses and material waste; expensive to make and to install; not aesthetically appealing, nor easily integrated into roofs or facades; fragile means they could easily be vandalised [3]. Building integration of city solar systems is essential, and some recent investigations have been closely focused on this [4]. By integrating unique polyethylene heat exchanger loop into a novel roof construction to form a "Sandwich" Thermal Roof Collector could be an efficient alternative to overcome those drawbacks of conventional solar thermal collectors. "Sandwich" Thermal Roofs, as solar absorbers, would be used to maximize the solar heat energy absorption. It is wise to say that roofs have great solar thermal potential due to their large size, free from shadowing and orientation limitations [5].

For heat pumps, a fundamental factor of great importance for highly efficient operation is the availability of a cheap, reliable heat source for the evaporator. The power quality can be improved by coupling solar energy with heat pump and the combination can represent interesting solutions for various domestic applications. The evaporator-collector employed in such a system can absorb both solar thermal and ambient energy [6]. Series of experiments were conducted with R 22 and 134a to identify proper refrigerant [7]. Solar assisted heat pump systems (SAHP) to produce hot water have been widely investigated in both theoretical and experimental studies. To name a few, considerable amount of study, both theoretical and experimental, on the exergetic performance evaluation of heat pumps systems with various heat sources [8] like ground heat, solar heat and heat recovery[9], heat pump system having PV/T evaporator [10], solar assisted heat pump with an energy storage [11], on a direct-expansion solar-assisted heat pump water heating system [12], and heat pump systems for district heating [13]. The measurements have been undertaken to discover the building space heating capabilities of the solar assisted heat pump systems [14], [15]. Experimental performance analysis of a solar assisted ground-source heat pump for green house heating [16] and the development and performance analysis of absorption heat pump system driven by solar energy [17] have been analysed. Solar assisted heat pump applications and performance assessments for agricultural and marine products drying have been reviewed and concepts have been introduced [18].

Combination of the heat pump and solar energy is a mutual beneficial way of enhancing the coefficient of performance of a heat pump and solar collector efficiency. The heat pump COP can be elevated to the great extent on the temperature of the evaporator. The solar collector loop enables to boost the heat source temperature of the heat pump, thereby improving the annual and seasonal performance of the heat pump. COP value about 6.38 experimentally obtained in a SAHP domestic heating system with an evacuated tubular 
collector [19]. The COP value was attained as 9 in a SAHP water heating system using unglazed flat-plate collectors [6]. The average COP of heat pump system for agricultural drying was found to be 7 in tropics [16].

Exergy analysis is a primary thermodynamic performance evaluation of energy systems in addressing the impact of energy resource utilization on the environment. It is an effective technique to determine the actual magnitude of wastes and losses for more efficient use of energy resources via applying conservation of mass and energy principles along with the second law of thermodynamics [8].

\subsection{Objective}

The objective of this study is to achieve a roof integrated thermal "Sandwich" solar thermal roof collector that properly blends into surrounding thus avoiding 'add on' appearance and having a dual function (heat absorption and roofing). Even though a low cost 'Sandwich' roof may produce lower fluid temperatures than water based glazed collectors, it is able to absorb and emit heat from the ambient via convection, and solar radiation. Another objective is to address the inherent technical pitfalls and practical limitations of conventional solar thermal collectors by bringing an inexpensive, maintenance free and easily adaptable solution. Although substantial studies have been performed on the combination of solar PV modules with heat pumps, integration of such a novel roof construction with heat pump has yet to be considered. The present study will both theoretically and experimentally evaluate the thermal performance of the "Sandwich" roof unit with heat pump. 


\begin{tabular}{|c|c|c|c|}
\hline \multicolumn{4}{|c|}{ Nomenclature } \\
\hline & Effective area, $\mathrm{m}^{2}$ & $c p, e$ & electrical energy in compressor \\
\hline & Specific heat & cs & collector side \\
\hline & ${ }^{D}$ Coefficient of Performance & $c, t$ & thermal energy in condenser \\
\hline & Outer diameter of heat exchanger tube, $\mathrm{m}$ & $c v$ & convective \\
\hline$G_{r}$ & Grashoff number & $e$ & evaporator \\
\hline$g$ & Gravitational acceleration, $\mathrm{m} / \mathrm{s}^{2}$ & $e, t$ & thermal energy from evaporator \\
\hline$h$ & Heat transfer coefficient, $\mathrm{W} / \mathrm{m}^{2} \mathrm{~K}$ & $f$ & fluid \\
\hline$I$ & Incident solar radiation, $\mathrm{W} / \mathrm{m}^{2}$ & he & heat exchanger \\
\hline$K$ & Thermal conductivity & hein & inner wall of heat exchanger \\
\hline & Mean flow rate & heo & outer wall of heat exchanger \\
\hline & Nusselt number & heo, hein & outer wall to inner wall of heat exchanger \\
\hline$W$ & Distance between tubes & hein, $r$ & inner wall of heat exchanger to refrigerant \\
\hline$\dot{W}$ & Compressor power $(\mathrm{kW})$ & $H P$ & heat pump \\
\hline & Wind speed, $\mathrm{m} / \mathrm{s}$ & $l$ & loss \\
\hline & & $l s$ & load side \\
\hline \multicolumn{2}{|c|}{ Greek Letters } & $p$ & pipe \\
\hline \multicolumn{2}{|c|}{$\alpha \quad$ absorption } & $r$ & refrigerant \\
\hline \multicolumn{2}{|c|}{$\delta \quad$ thickness, $\mathrm{m}$} & $r d$ & radiative \\
\hline \multicolumn{2}{|c|}{$\eta \quad$ efficiency, $\%$} & $s$ & sky \\
\hline \multicolumn{2}{|c|}{$\lambda$ thermal conductivity, $\mathrm{W} / \mathrm{m}^{2} \mathrm{~K}$} & $S Y S$ & system \\
\hline \multicolumn{2}{|c|}{$\Sigma$ total } & $t$ & thermal \\
\hline б & Stefan-Boltzmann constant & $\begin{array}{l}t, n e t \\
w\end{array}$ & $\begin{array}{l}\text { net thermal } \\
\text { water }\end{array}$ \\
\hline \multicolumn{4}{|c|}{ Subscripts } \\
\hline$a$ & ambient air & & \\
\hline \multicolumn{2}{|c|}{ abs absorber surface } & & \\
\hline \multicolumn{2}{|c|}{$c \quad$ cover layer } & & \\
\hline \multicolumn{2}{|c|}{ cn condenser } & & \\
\hline
\end{tabular}




\section{Description of the "Sandwich" Roof unit and its combined operation with heap pump}

The combination of solar thermal roof collector and heat pump system consists of a Thermal "Sandwich" Roof collector that acts as both roof for a dwelling and heat source for the heat pump. Thereby, the roof module contains several layers, namely the outer surface is a black painted aluminium solar radiation absorber, polyethylene heat exchanger loop tightly bolted to the black aluminium surface for enhanced heat transfer and injected insulation foam back layer against heat loss. Furthermore, thermally conducting adhesion was used to improve the heat transfer between the aluminium cover and poly heat exchanger pipes. By this means, all layers are integrated into the same module to form a "Sandwich" Thermal Roof collector.

In the roofing structure, steel frames form a roof truss which weighs and fits the modules to build up a wellintegrated roof. As for the plumbing of the system, supply and return pipes are placed underneath the roof truss and joined using flexible coupled connectors with valves to provide a leak free connection. In doing so, the supply pipe feeds cold water to polyethylene heat exchanger, and the return pipe transports the hot water from heat exchanger. To some extent, the sandwich module and roof support are well fixed together to form a properly functional solar thermal roof. Fig 1 is the illustration of layers of "Sandwich" Thermal Roof Collector.

Fig. 1 Cross sectional view of the Novel "Sandwich" Thermal Roof Collector

In operation, the "Sandwich" module receives a substantial amount of solar insolation falling upon the black coated solar absorbing surface as a means of thermal energy, while dispersing remainder to the surrounding. The black painted aluminium top cover enhances the solar heat absorption. As the second law of thermodynamics states that when an object is at a different temperature from its surroundings, heat flows so that the body and surroundings reach the same temperature, at which they are in thermal equilibrium. Such a spontaneous heat transfer occurs from high temperature to low temperature. Thus, setting the surface at a lower temperature than the surrounding by circulating cold water will cause to the heat flow, thermodynamically, moves towards roof module. The absorbed heat, then, will be conveyed through the circulating water across the heat exchanger. Consequently, enhanced solar thermal efficiency would be expected. Moreover, fixing the tubes and risers of polyethylene heat exchanger tightly to the black aluminium surface would potentially lead to having relatively low temperature difference between the module surface and heat carrying water. The hot water obtained out of this operation can be utilized for space heating \& cooling, domestic hot water supply, food drying, assisting natural ventilation inside a building and/or other services. 
The system also comprises $3 \mathrm{~kW}$ thermal output commercially available heat pump package designed for space heating and domestic hot water for buildings. The HP system includes a solar thermal collector/evaporator, compressor, condenser, and an expansion valve. In operation, the "Sandwich" structure roof unit/evaporator draws a free, low grade renewable energy from solar heated water for heat pump to evaporate the refrigerant in compressor. The compressor transforms the low temperature saturated refrigerant vapour into high temperature, super saturated vapour. On the condenser, the working fluid releases the energy in the form of heat to the space heating water. The heat, then, conveyed by water, as a heat carrier, could be used for heating, cooling, domestic hot water supply and other needs. The schematic diagram of the solar assisted heat pump space heating system, using environmentally friendly R134a refrigerant which has practically the same behaviour as other refrigerants in terms of temperature variation and compressor frequency, is given in Fig 2 below. The technical parameters of the absorber, heat exchanger and heat pump can be found in Table 1.

Fig. 2 Schematic of the combined system

Table 1 Technical parameters

\subsection{Prototype Design}

A prototype of the combination of solar thermal roof and heat pump system was assembled and tested both in the laboratories of Institute of Sustainable Energy Technology at the University of Nottingham and under the prevailing climatic conditions of Nottingham, UK which is geographically located at $52.57^{\circ} \mathrm{N}$ and $1.09^{\circ} \mathrm{W}$. The key innovation in the proposed system is the utilization of the solar thermal energy as a renewable source with relatively efficient and low cost components by a thermodynamically effective design. The size of the "Sandwich" collector is large enough to be tested so that the performance characteristics can be detected properly. Initial design parameters are given in Table 2 below. Fig. 4 shows the schematic diagram of the roof system.

As absorber, $5 \mathrm{~mm}$ thick aluminium cover was coated with high temperature silicone spray for enhanced solar thermal absorption. As heat extraction component, polyethylene heat exchanger loop was tightly fixed to the black aluminium surface to have a good touch to the absorber for enhanced heat transfer. As roof finishing, insulation foam was injected as back layer against heat loss. 
The heat exchanger loop is made of polyethylene thermoplastic substance and its physical structure makes it first-of-its-kind. The pipes and fittings were incorporated via welding with soldering iron. The flow channels have $2.7 \mathrm{~mm}$ of internal and $4.3 \mathrm{~mm}$ of external diameters and the distance between the flow channels is $10 \mathrm{~mm}$. Technical parameters of the heat exchanger can be found in Table 1.

The heat pump unit was connected to a 551 storage tank with a circulation pump and a flow meter regulator to modulate the mass flow rate of hot water. The storage tank was thoroughly insulated with foam insulation material in order to reduce the heat losses. The water inside the storage tank was heated by employing a helical copper tubular heat exchanger. An expansion vessel was also installed in between the heat pump and storage tank coupling to reduce the likely damages due to excessive increase in pressure, and also the fluid pressure in the solar thermal roof unit is monitored by a pressure gauge, as shown in Fig. 2.

The circulating pumps employed in close loop solar roof systems must overcome the head pressures. Also, the pump should be compatible with solar applications in terms of its size, speed, efficiency, and hydraulics and power consumption. Technical details of the circulation pump are provided in Table 1.

An array of 30 halogen floodlights was employed in order to simulate the artificial solar sunlight. The solar sunlight simulator was evenly fixed on an aluminium frame installed above and in parallel to the "Sandwich" roof, as illustrated in Fig. 2. The array was formed as three sub arrays and was connected to the grid through a 3phase transformer, which allows the level of the radiation flux to be gradually regulated. The maximum electrical power to be consumed by each floodlight is $400 \mathrm{~W}$. A Kipp \& Zonen pyranometer with sensitivity of $17.99 \times 10^{-6} \mathrm{~V} / \mathrm{W} / \mathrm{m}^{2}$ was mounted on the vertical surface to measure the radiation flux on the surface of the novel roof. An anemometer was also installed for outdoor test. K type thermocouples were inserted to investigate the temperature variation across system. All related data was recorded on the data logger, DT500 and direct connection between data logger and PC was provided to store data and export on Excel spreadsheet.

Fig. 3 Experimental Design - Novel Solar Thermal roof with Solar Simulator, Heat Pump, Water Storage 


\section{Mathematical Modelling and EES Model set-up}

Energy transfer arose within the proposed system has two major processes including conversion of solar radiation into thermal energy by "Sandwich" roof unit and upgrading the evaporation heat into higher grade energy through the heat pump. These two processes are interconnected and eventually reach a balance under the steady state operation. A numerical model which is well suited to the physical structure of the proposed system was adapted to simulate the thermal performance of the novel system by using EES (Engineering Equation Solver) Software. Several assumptions have been considered during the first and second law analyses of the system as follows:

a) The overall performance of the system is at a quasi-steady state condition with negligible potential and kinetic energy effects and there is no chemical reactions taken for all processes.

b) All surfaces of layers cover uniform temperature and temperature gradient around tubes is negligible.

c) There is forced flow through heat exchanger tubes and the pressure drop is negligible due to the short length of pipelines.

d) Due to advanced thermal resistance features, heat loss through the insulation and edge is negligible

The method and mathematical equations presented in this study are not necessarily the most accurate available; but, they are widely applied, easy to use and adequate for most of the design computation. Heat transfer profile of the roof unit and P-h chart of the refrigeration cycle are shown in Fig 4 and Fig 5, respectively.

Fig. 4 The heat transfer profile of the roof unit

Fig. $5 \mathrm{P}-\mathrm{H}$ chart of the heat pump refrigeration cycle

\subsection{Energy Analysis of "Sandwich” Roof Unit}

Initially incoming Solar Energy is defined as [20];

$$
Q_{a b s}=\alpha_{a b s} \cdot A_{e f f} \cdot I
$$

Heat loss is mainly through the top due to the good back insulation features of "Sandwich" Roof unit. So the heat loss can be expressed as [20]; 
$Q_{l}=h_{c} \cdot\left(T_{a b s}-T_{a}\right)+\varepsilon_{a b s} \cdot \sigma \cdot\left(T_{a b s}{ }^{4}-T_{s k y}{ }^{4}\right)$

Combining above equations provides a revised expression of the useful heat energy $\left(\mathrm{Q}_{\mathrm{t}}\right)$ :

$Q_{t}=Q_{a b s}-Q_{l}$

The natural convection heat transfer coefficient $\left(h_{\mathrm{c}}\right)$ from roof to the ambient is taken into account for wind velocities lower than or equal to $6 \mathrm{~m} / \mathrm{s}(V)$ by [21];

$h_{c}=6.5+3.3 \cdot V$

The sky temperature can be obtained by Swinbank equation as a function of the ambient temperature by [20];

$T_{s k y}=0.037536 \cdot T_{a}^{1.5}+0.32^{T_{a}}$

Radiation heat transfer through the front is defined as;

$h_{r d}=\varepsilon_{c} \cdot \sigma \cdot\left(T_{a b s}{ }^{4}-T_{s k y}{ }^{4}\right)$

The heat flow goes through conduction across the absorber (black aluminum), the walls of heat exchanger tubes and is eventually conveyed to the refrigerant. The heat gain of refrigerant is as equal as the useful heat energy as [20];

$Q_{t}=A_{e f f} \cdot U_{t} \cdot\left(T_{a b s}-T_{w}\right)$

Overall heat transfer coefficient between absorber and refrigerant is [20];

$U_{t}=\left(U_{\text {abs,heo }}+U_{\text {heo,hein }}+U_{h e i n, w}\right)^{-1}$

Heat transfer coefficient ( $\mathrm{U}_{\mathrm{abs}, \mathrm{heo}}$ ) from absorber aluminum layer to outer wall of heat exchanger is by [20];

$U_{a b s, h e o}=\frac{\lambda_{a b s}}{\delta_{a b s}}$

The temperature at the outer wall of the polyethylene heat exchanger becomes [20] 


$$
T_{\text {heo }}=T_{a b s}-\frac{Q_{t}}{A_{e f f} \cdot U_{a b s, h e o}}
$$

Heat transfer coefficient $\left(\mathrm{U}_{\text {heo, hein }}\right)$ from outer wall to interior wall of heat exchanger is defined as [20];

$$
U_{\text {heo,hein }}=\frac{2 \cdot \pi \cdot \lambda_{\text {he }}}{\ln \left[\frac{D_{o}}{D_{i}}\right]}
$$

The average temperature at the inner wall of polyethylene heat exchanger is given as [20];

$$
T_{\text {hein }}=T_{\text {heo }}-\frac{Q_{t}}{A_{e f f} \cdot U_{\text {heo,hein }}}
$$

Heat transfer coefficient $\left(\mathrm{U}_{\text {hein, } \mathrm{r}}\right)$ from interior wall of heat exchanger to water [20];

$U_{h e i n, r}=\frac{N u_{r} \cdot \lambda_{r}}{D_{i}}$

Where Nusselt number is expressed as [20];

$$
N u_{r}=0.023 \cdot \operatorname{Re}_{r}{ }^{0.8} \cdot \operatorname{Pr}_{r}{ }^{0.4}
$$

The Reynolds number for flows in pipe or tube is generally defined as [20];

$$
\operatorname{Re}_{r}=\frac{\dot{Q} \cdot D_{h e}}{V_{r} \cdot A_{p}}
$$

In order to compare the theoretical results with the experimental outcomes, the root mean square percent deviation $(e)$ and the coefficient of correlation $(r)$ have been examined by using the following expressions [20];

$$
\begin{aligned}
& e=\sqrt{\frac{\Sigma\left(e_{i}\right)^{2}}{N} \text { where } e_{i}=\left[\frac{X_{i}-Y_{i}}{X_{i}}\right] \times 100} \\
& r=\frac{n(\Sigma X \times Y)-(\Sigma X) \times(\Sigma Y)}{\sqrt{n\left(\Sigma X^{2}\right)-(\Sigma X)^{2}} \times \sqrt{n\left(\Sigma Y^{2}\right)-(\Sigma Y)^{2}}}
\end{aligned}
$$


Stating the expressions used by [20]

$m^{2}=\frac{U_{t}}{K \delta}$

Then, the fin efficiency factor (F) can be found by

$$
F=\frac{\tanh m \frac{W-D_{o}}{2}}{m \frac{W-D_{o}}{2}}
$$

The flat plate collector efficiency $\left(F^{\prime}\right)$ becomes

$$
F^{\prime}=\frac{1}{\frac{W U_{t}}{D_{o} U_{a b s, p l}}+\frac{W U_{t}}{\frac{K}{\delta}}+\frac{W U_{t}}{D_{o}+\left(W-D_{o}\right) F}}
$$

The flow rate factor $\left(F_{R}\right)$ is given by

$$
F_{R}=\frac{\dot{m} C_{f}}{A_{e f f} U_{t} F^{\prime}}\left[1-\exp \left(-\frac{A_{e f f} U_{t} F^{\prime}}{\dot{m} C_{f}}\right)\right]
$$

Energy efficiency is usually defined as the ratio of total energy output to the total energy input as

$$
\eta=\frac{\dot{E}_{\text {out }}}{\dot{E}_{\text {in }}}
$$

\subsection{Energy Analysis of Heat Pump Unit}

The water from the Novel solar thermal roof circulates through the evaporator in the heat pump. There it releases heat to liquid refrigerant passing separately across the evaporator, allowing the environmentally friendly refrigerant R-134a to vaporise. The water then returns to the solar thermal collector to capture heat again in a continuous cycle. The preheated refrigerant vapour goes through the compressor, where it is compressed to high pressure and upgraded to a much higher temperature. High temperature vapour, then, passes 
through the condenser where it is surrounded by water from the heating system and releases heat to the water circulating via channels. Consequently, vapour becomes saturated liquid with a same pressure. The temperature and pressure of the refrigerant is further reduced by flowing through the expansion device, from where it turns back to the evaporator to repeat the cycle.

The heat received by the evaporator $\left(Q_{e}\right)$ is given by the following equation [23]:

$$
Q_{e}=m_{r} \cdot\left(H_{1}-H_{4}\right)
$$

The heat introduced to the condenser $\left(Q_{c)}\right.$ is given by [23]:

$$
Q_{c}=m_{r} \cdot\left(H_{1}-H_{4}\right)
$$

The electrical power required to drive the compressor $\left(Q_{c p, e}\right)$ is given by [23]:

$$
Q_{c, e}=m_{r} \cdot\left(H_{2}-H_{1}\right)
$$

Coefficient of performance of the heat pump $\left(\mathrm{COP}_{\mathrm{HP}}\right)$ is given by [11]:

$$
C O P_{H P}=\frac{Q_{c}}{W_{c p}}
$$

Coefficient performance of the overall system (COPSYS) is the ratio of condenser load to the total power consumption of the compressor and other two circulation pumps and it is given by [11]:

$$
C O P_{S Y S}=\frac{Q_{c}}{W_{c p}+W_{c s}+W_{l s}}
$$

\subsection{Uncertainty Analysis}

The experimental uncertainties were determined by applying Gauss propagation law. The result $\mathrm{R}$ is calculated as a function of the independent variables $\mathrm{x}_{1}, \mathrm{x}_{2}, \mathrm{x}_{3}, \ldots, \mathrm{x}_{\mathrm{n}}$ and $\mathrm{w}_{1}, \mathrm{w}_{2}, \mathrm{w}_{3}, \ldots, \mathrm{w}_{\mathrm{n}}$ represents the uncertainties in the independent variables. Then, uncertainty $\mathrm{R}$ is expressed as [20]: 
$w_{R}=\left[\left(\frac{\partial R}{\partial x_{1}} w_{1}\right)^{2}+\left(\frac{\partial R}{\partial x_{2}} w_{2}\right)^{2}+\ldots+\left(\frac{\partial R}{\partial x_{n}} w_{n}\right)^{2}\right]^{1 / 2}$

The independent parameters measured in the experiments are: solar radiation, temperature of solar thermal roof, temperature of water, ambient temperature, flow rates and power consumption of the heat pump. Experiments were conducted by using following instruments: a Kipp and Zonen CM11 pyranometer with $1 \%$ accuracy, Ktype thermocouples with the maximum deviation of $\pm 0.3^{\circ} \mathrm{C}$, liquid flow indicators with the accuracy of $\pm 2 \%$ and a watt meter with $\pm 2 \%$ accuracy.

It is obtained from the equations (1), (2), (3), (6), (10), and (13) that the $\eta_{\mathrm{t}}$ is the function of several variables, each subject to uncertainty:

$\eta_{t}=f\left(T_{w}, T_{a b s}, T_{a}, \dot{m}, I, \dot{W}_{\Sigma p}\right)$

Total uncertainty for overall system efficiency can be expressed as;

$w_{R}=\left[\left(\frac{\partial \eta}{\partial \delta_{\text {air }}} w_{\delta_{\text {air }}}\right)^{2}+\left(\frac{\partial \eta}{\partial T_{a}} w_{T_{a}}\right)^{2}+\left(\frac{\partial \eta}{\partial V} w_{V}\right)^{2}+\left(\frac{\partial \eta}{\partial I} w_{I}\right)^{2}\right]^{1 / 2}$

Total uncertainty rate affecting the efficiency of the proposed system was computed by using Eqs. (28)-(30).

The estimation implies that total uncertainty in calculation of the efficiency is found to be $4.08 \%$.

\section{Results and Analysis}

The theoretical analysis and experimental investigation were performed to evaluate the performance of the solar sandwich roof along with a heat pump unit. In analysis, the effects of the various operating parameters including thermal and overall efficiencies on the performance of the envisaged system were also investigated. The developed mathematical model to describe the system operation was programmed by using Engineering Equation Solver software (EES, 2013). In this software, energy and mass balance equations and the boundary conditions are solved simultaneously. In order to validate the mathematical model, the theoretical and experimental results were compared and shown that there is rather a good compliance between them. One should note that due to climatic constraints, outdoor testing was performed only one day on $23^{\text {rd }}$ of June. From the experimental data, the temperature of the water outlet from the innovative solar thermal collector, the mean 
values of the COP of the heat pump and of the overall system and efficiency ratios were deduced and presented in Table 3.

The novel solar thermal roof unit presented in Fig. 1 was experimentally investigated to test the system performance under various solar intensities employing the solar simulator to control the incoming solar radiation. Fig. 6 represents the performance of the "Sandwich" thermal collector under $400 \mathrm{~W} / \mathrm{m}^{2}$ and 2-6 1/min water flow rates. The surface temperature ranges between 20.5 and $32.3^{\circ} \mathrm{C}$ with a flowing water temperature in the range of 10.6 and $16.2^{\circ} \mathrm{C}$ and a maximum temperature increase of $5.6^{\circ} \mathrm{C}$. One should note that maximum temperature increase is achieved while flow rate is $21 / \mathrm{min}$ and the least is noted as the flow rate is $61 / \mathrm{min}$.

Fig. 6Performance of the novel roof under $400 \mathrm{~W} / \mathrm{m}^{2}$ solar intensity and various flow rates

Fig. 7 represents the performance characteristics of the "Novel" roof under $600 \mathrm{~W} / \mathrm{m}^{2}$ and water flow rates of 2$6 \mathrm{l} / \mathrm{min}$. The surface temperature reaches up to $52.4^{\circ} \mathrm{C}$ and the maximum surface temperature increase is attained as $19.3^{\circ} \mathrm{C}$. Heat carrying water flowing through tubes and risers of the polyethylene heat exchanger has the temperature range of 17.6 and $26.2^{\circ} \mathrm{C}$ as maximum temperature increase is $13^{\circ} \mathrm{C}$ while the water flow rate is 2 $1 / \mathrm{min}$.

Fig. 7 Performance of the novel roof under $600 \mathrm{~W} / \mathrm{m}^{2}$ solar intensity and various flow rates

Fig. 8 presents the associated performance findings of the proposed solar thermal roof under $800 \mathrm{~W} / \mathrm{m}^{2}$ solar insolation and 6,4, and 2 1/min water flow rates, respectively. The surface temperature ranges between $55.5^{\circ} \mathrm{C}$ and $66.5^{\circ} \mathrm{C}$ with a flowing water temperature in the range of $27.67^{\circ} \mathrm{C}$ and $35.02^{\circ} \mathrm{C}$ and a maximum temperature increase is of $20^{\circ} \mathrm{C}$.

Fig. 8 Performance of the novel roof under $800 \mathrm{~W} / \mathrm{m}^{2}$ solar intensity and various flow rates 
Fig. 9 presents the efficiency change of the "Novel" solar thermal collector under various solar radiation and water flow rates. It can be seen from the graph that although higher flow rate has the greater efficiency ratios for low solar insolation settings, slower flow rate such as $21 / \mathrm{min}$ has the superior efficiency ratios for the higher solar radiation levels. As incoming solar radiation to the roof system increases, the efficiency level also increases with the slower flow rates.

Fig. 9 Variation of efficiency under different solar radiation with various flow rates

Fig. 10 presents the collector efficiency as a function of the flowing fluid, air temperature and solar radiation on the surface. The thermal efficiency is inversely proportional to the increasing $\left(\mathrm{T}_{\mathrm{w}}-\mathrm{T}_{\mathrm{a}}\right) / \mathrm{I}$ ratio. Any momentarily change in climatic conditions could have variuos impacts over the thermal efficiency of the roof unit as follows; when the air temperature is relatively low, this may lead to more heat disspation from hot surface to the ambient, thus causing to lower thermal efficiencies. Higher solar radiation contributes to enhanced heat transfer from black aluminium surface towards the polyethylene heat exchanger layer and this will eventually conduce to greater thermal efficiencies of the Novel roof. Also, high temperature of flowing water through the heat exchanger results in low efficiencies due to reduced heat transfer across the poly heat exchanger and confined structure of the "sandwich" roof prevents high heat dissipation towards environment.

Fig. 10 Effect of collector fluid temperature on the collector efficiency

\subsection{Outdoor Testing}

\subsubsection{Solar Roof}

Fig. 11 presents the environmental conditions on $23^{\text {rd }}$ of June that outdoor test has been performed, outer surface and water temperatures varying depending on the external conditions. The wind speed is measured over the course of the external test to find out the heat flow rate through natural convection between the blackened aluminium surface and the surroundings. Average solar radiation (I), ambient air temperature (Ta), and wind speed on $23^{\text {rd }}$ of June are measured as $701.3 \mathrm{~W} / \mathrm{m}^{2}, 27.3^{\circ} \mathrm{C}$, and $1.09 \mathrm{~m} / \mathrm{s}$, respectively. It is clearly shown in 
Fig. 11 that the surface temperature is expectedly higher than the circulating water temperature. Around $9{ }^{\circ} \mathrm{C}$ increase in water temperature is noted while the surface temperature is in the range between $22.6^{\circ} \mathrm{C}$ and $44.6^{\circ} \mathrm{C}$. One may conclude that conceiving the changes in temperature tendencies and increase in both surface and water temperature, there seems to be a fair agreement with the results obtained.

Fig. 11 Hourly variation of temperature Ta, Ts, Tw and wind speed Vwind (23th June)

The design parameters in Tables 1-2 and climatic data have been utilized to assess the water and surface temperatures in Fig. 11-13. The root mean square percent deviation and correlation coefficient obtained by Eqs. (16) \& (17) have also been evaluated and presented in the same figures. Fig. 12 presents the comparison between experimental and theoretical values of the surface temperature. The results indicate that predicted and experimental results are in a good agreement as the correlation coefficient and root mean square values are attained as 0.88 and $4.55 \%$, respectively. Fig.13 also presents the comparison between the theoretical and experimental results regarding the water temperature increase as a result of circulating within the heat exchanger being heat extraction component of the novel roof. Data gathered from the analysis show that the results obtained from the numerical investigation are in good compliance with the results of the experimental study. The correlation coefficient and root mean square values for water temperature comparison are attained as 0.92 and $3.03 \%$. So, the estimated and experimental results for surface and water temperatures were found to be closely correlated.

Fig. 12 Hourly variation of surface temperature - theoretical vs experimental

Fig. 13 Hourly variation of water temperature - theoretical vs experimental 


\subsubsection{Heat Pump}

Fig. 14 presents the experimental data plotted on $23^{\text {rd }}$ of June regarding the COP, power consumption of the heat pump, and heat gain in condenser changing with respect to time. The water temperature at the condenser set constant at $35^{\circ} \mathrm{C}$ for space heating purpose. From results, the energy gain at the condenser is in the range of 1.9 $\mathrm{kW}$ to $3.43 \mathrm{~kW}$ while the $\mathrm{COP}$ is fluctuated between 2.4 to 3.1 . Meanwhile, the energy consumption is noted average of $0.7 \mathrm{~kW}$ in the test day.

Fig. 14 Test result obtained on 23th of June

Fig. 15 presents the temperature variation in the water storage tank versus time of the day. The temperature difference observed between the top and bottom of the storage tank is up to $4{ }^{\circ} \mathrm{C}$. However, the temperature deviation tends to decrease gradually.

Fig. 16 presents the COP of the heat pump versus COP of the overall system in the test day. The COP of the heat pumps is found to be higher than that of the overall system COP. The heat pump COP ranges between 2.4 and 3.1 while system COP is from 1.7 to 2.5 , respectively. Daily average values of the measurements taken from $8 \mathrm{am}$ to $5 \mathrm{pm}$ are provided in Table 3.

Fig. 15 Temperature variation in energy storing with time

Fig. 16 Coefficient of Performance variation by time 


\section{Conclusion}

A Novel solar thermal roof collector coupled with a heat pump unit was investigated by simulation and experimental methods. The performance test results and energy evaluation analysis were presented. The numerical models were validated by the experimental findings collected on $23^{\text {rd }}$ June. Also, the impacts of environmental conditions and operating parameters were examined. The concluding remarks are outlined as followings;

The selection of the heat pump unit was mainly because of its good compliance with the operating conditions, economic viability and environmental impacts, etc. Although initial costs of the heat pump systems are usually high, their low operating, maintenance and life cycle costs and long life cycle expectancy attract considerable interest as a potential alternative to the most conventional systems.

The validation of the developed thermal model was carried out by comparing the theoretical results with the actual findings during experiments. As the comparison indicates, thermal model developed for this prototype has a good agreement with the experimental results obtained.

Overall results prove that the flowing water through tubes and risers of the heat exchanger layer can successfully convey the solar thermal energy and have a cooling effect on the roof surface. The initial tests conducted at the laboratory environment show that the solar roof collector yields the maximum of $32.3^{\circ} \mathrm{C}$ surface temperature and $17.6^{\circ} \mathrm{C}$ water temperature at $400 \mathrm{~W} / \mathrm{m}^{2}$ solar radiation, $52.4^{\circ} \mathrm{C}$ surface temperature and $25^{\circ} \mathrm{C}$ water temperature at $600 \mathrm{~W} / \mathrm{m}^{2}$ solar radiation and lastly $66.5^{\circ} \mathrm{C}$ surface temperature and $32^{\circ} \mathrm{C}$ water temperature at $800 \mathrm{~W} / \mathrm{m}^{2}$ solar radiation, respectively. Although the flow rate of $2 \mathrm{l} / \mathrm{min}$ seems nominal at first instance, capturing heat slowly from the surface causes to happen overheating of the surface. This, however, may result in exceeding the maximum temperature threshold for the heat exchanger and may be harmful the rise and pipes. To minimize this conflicting trend, the tests were initiated with the water flow rate of $61 / \mathrm{min}$ for cooler surface then flow rates were gradually reduced until $21 /$ min throughout the test season. Hence, the optimum flow rate was assumedly taken as $4 \mathrm{l} / \mathrm{min}$ for outdoor test of the system. As for the outdoor performance test on $23^{\text {rd }}$ June, the temperature of water could increase up to $30^{\circ} \mathrm{C}$. Thus, temperature increase of the water circulating through the innovative roof module could get up to $10^{\circ} \mathrm{C}$ when the liquid within the system is around at around $20^{\circ} \mathrm{C}$. The efficiency of the solar thermal collector varies between 0.24 and 0.11 , respectively. Experimentally obtained results present that the proposed solar thermal collector can act as an efficient heat extraction component for solar source heat pump systems. 
The COPs of the heat pump and overall system are calculated in terms of experimental data obtained from the outdoor test. Overall COP values of the system increase with the ambient air temperature and solar radiation and reach a maximum at 3.2 at an average of 2.98 over the course of testing. The maximum heat transfer rate experimentally attained in the condenser is $3.43 \mathrm{~kW}$.

The performance investigation of the system reveals that substantial amount of energy can be saved by utilizing solar thermal energy when implementing such a novel system. This new system may also provide a simple yet effective alternative for regions suffering from energy scarcity in the residential and commercial areas.

Solar assisted heat pump systems also provide enormous environmental benefits as they don't exhaust natural resources, and mostly do not allow any kind of air emissions or waste products. Therefore, these systems may also contribute to mitigation of the environmental pollution and provide a remedial action especially in the areas where air emissions arise in dangerous levels [24].

\section{Acknowledgements}

The authors would like to gratefully acknowledge that this research was supported financially and in-kind by the Institute of Sustainable Energy Technology, University of Nottingham. 


\section{References}

[1] Amin, Zakaria Mohd, and M. N. A. Hawlader. "A review on solar assisted heat pump systems in Singapore." Renewable and Sustainable Energy Reviews 26 (2013): 286-293.

[2] Chua, K. J., et al. "Heat pump drying: Recent developments and future trends. "Drying Technology 20.8 (2002): 1579-1610.

[3] Buker, M.S., Mempouo, B., Riffat, S. (2013). "Theoretical Investigation of the Thermal Performance of a Novel Building Integrated PV/Thermal Roof Collector.” SET 2013 International Symposium on Sustainable Energy Technologies, August, 26-29, Hong-Kong, China.

[4] Kalogirou, Soteris A. "Building integration of solar renewable energy systems towards zero or nearly zero energy buildings." International Journal of Low-Carbon Technologies (2013): ctt071.

[5] Stasinopoulos, Thanos N. "Sunny walls vs sunnier roofs: a study on the advantages of roofs for solar collection." Environmental Management and Health13.4 (2002): 339-347.

[6] Hawlader, M. N. A., S. K. Chou, and M. Z. Ullah. "The performance of a solar assisted heat pump water heating system." Applied Thermal Engineering 21.10 (2001): 1049-1065.

[7] Abou-Ziyan, H. Z., et al. "Solar-assisted R22 and R134a heat pump systems for low-temperature applications." Applied Thermal Engineering 17.5 (1997): 455-469.

[8] Dikici, Aydın, and Abdullah Akbulut. "Exergetic performance evaluation of heat pump systems having various heat sources." International Journal of Energy Research 32.14 (2008): 1279-1296.

[9] Busato, Filippo, Renato M. Lazzarin, and Marco Noro. "Multisource heat pump system from design to operation: the case study of a new school building."International Journal of Low-Carbon Technologies 8.2 (2013): 88-94.

[10] Ji, Jie, et al. "Thermal analysis of PV/T evaporator of a solar-assisted heat pump." International journal of Energy Research 31.5 (2007): 525-545. 
[11] Yumrutas, Recep, and Önder Kaska. "Experimental investigation of thermal performance of a solar assisted heat pump system with an energy storage." International journal of energy research 28.2 (2004): 163175.

[12] Kuang, Y. H., K. Sumathy, and R. Z. Wang. "Study on a direct-expansion solar-assisted heat pump water heating system." International Journal of Energy Research 27.5 (2003): 531-548.

[13] Hepbasli, Arif. "Thermodynamic analysis of a ground-source heat pump system for district heating." International Journal of Energy Research 29.7 (2005): 671-687.

[14] Yang, Zhiyong, Yiping Wang, and Li Zhu. "Building space heating with a solar-assisted heat pump using roof-integrated solar collectors." Energies 4.3 (2011): 504-516.

[15] Bakirci, Kadir, and Bedri Yuksel. "Experimental thermal performance of a solar source heat-pump system for residential heating in cold climate region." Applied thermal engineering 31.8 (2011): 1508-1518.

[16] Ozgener, Onder, and Arif Hepbasli. "Experimental investigation of the performance of a solar-assisted ground-source heat pump system for greenhouse heating." International Journal of Energy Research 29.3 (2005): 217-231.

[17] Sözen, Adnan, Duran Altıparmak, and Hüseyin Usta. "Development and testing of a prototype of absorption heat pump system operated by solar energy."Applied Thermal Engineering 22.16 (2002): 1847-1859.

[18] Daghigh, Ronak, et al. "Review of solar assisted heat pump drying systems for agricultural and marine products." Renewable and Sustainable Energy Reviews14.9 (2010): 2564-2579.

[19] Çağlar, Ahmet, and Cemil Yamalı. "Performance analysis of a solar-assisted heat pump with an evacuated tubular collector for domestic heating." Energy and Buildings 54 (2012): 22-28.

[20] Buker, M. S., Mempouo, B., \& Riffat, S. B. (2014). Performance evaluation and techno-economic analysis of a novel building integrated PV/T roof collector: An experimental validation. Energy and Buildings, 76, 164175. 
[21] Sharples, S., and P. S. Charlesworth. "Full-scale measurements of wind-induced convective heat transfer from a roof-mounted flat plate solar collector." Solar Energy 62.2 (1998): 69-77.

[22] Atmaca, Ibrahim, and Sezgi Kocak. "Theoretical energy and exergy analyses of solar assisted heat pump space heating system." Thermal Science 00 (2013): 24-24.

[23] Li, Hong, and Hongxing Yang. "Energy and exergy analysis of multi-functional solar-assisted heat pump system." International Journal of Low-Carbon Technologies 5.3 (2010): 130-136.

[24] Lazzarin, Renato M. "Technological innovations in heat pump systems."International Journal of LowCarbon Technologies 2.3 (2007): 262-288. 